Protestantismo em Revista é licenciada sob uma Licença Creative Commons.

http://dx.doi.org/10.22351/nepp.v44i1.3375

\title{
Pirro e Cineias: por uma teoria do agir humano
}

\author{
Pyrrhus and Cineas: toward a human action theory
}

Josiana Barbosa Andrade*

\begin{abstract}
Resumo
Resenha de: BEAUVOIR, Simone de. Pirro e Cinéias. In: BEAUVOIR, Simone de. Por uma moral da ambiguidade. Rio de Janeiro: Nova Fronteira, 2005. p. 127-206.
\end{abstract}

"É sua existência que define sua essência". (BEAUVOIR, 2005, p. 180)

No mesmo ano em que Paris foi libertada da ocupação nazista (1944), Simone de Beauvoir publicou o seu primeiro ensaio filosófico: Pirro e Cinéias (Pyrrhus et Cinéas). Nele, a filósofa francesa reflete sobre o agir humano, trazendo à tona o paradoxo da condição de nossa existência. A obra foi dividida em duas partes. Primeiro, a pensadora escreve sobre a relação do ser humano com o mundo; em seguida, a relação do ser humano com os outros.

Citando Vida de Pirro, de Plutarco, Beauvoir realiza a abertura de seu livro. Na anedota escrita pelo biógrafo de Queroneia, Pirro, rei de Épiro, conversa com seu conselheiro Cineias, o sábio de Tessália. Ao longo da conversação entre o conquistador e o orador, Pirro fala sobre seus projetos de conquistas, mas Cineias sempre o pergunta: E depois? E depois de conquistarmos e dominarmos tudo? Pirro, com um sorriso, responde: Ah, meu caro, descansarei! Então, Cineias questiona: por que não descansar agora, uma vez que já possuímos condições para realizar esse privilégio, sem qualquer esforço? ${ }^{1}$

Cineias parece ter bom senso: para que partir se é para voltar? Para que iniciar se se deve terminar? Para que começar um ciclo sem fim? Mas se Pirro resolvesse ficar, o faria? Não é possível respondermos, já que o projeto humano é individual. Embora a resposta do sábio de Tessália seja sensata, Beauvoir levar-nos-á a repensar. É possível ao

[Texto recebido em junho de 2018 e aceito em julho de 2018, com base na avaliação cega por pares realizada por pareceristas ad hoc]

* Discente de Filosofia na Universidade Federal de Pelotas. E-mail: josyyandrade17@gmail.com

Resenha foi preparada e apresentada, inicialmente, para a disciplina de História de Filosofia Contemporânea, ministrada pelo prof. Luís Rubira.

1 PLUTARCH. Life of Pyrrhus. In: PLUTARCH. Parallel Lives. New York: Thomas Y. Crowel Co, 1909. p. 42-76. (The Complete Works of Plutarch) 
ser humano fechar-se a si mesmo? Ser indiferente, ser um estrangeiro no mundo, fugir do infortúnio, não criar laços, como pensava o Estrangeiro de sr. Camus? Somente se fôssemos uma inerte, mas nossa subjetividade não é inércia, e sim movimento para outro.

O Estrangeiro, porém, faz-nos reconhecer que "nenhum laço é inicialmente dado" (p. 138), assim como a própria indiferença. Ele esqueceu-se, mas Beauvoir lembrou-nos: não somos uma coisa, mas espontaneidade que deseja, que ama, que quer, que age. Sou "um projeto para mim rumo ao outro, uma transcendência" (p. 139). Com isso, para a filósofa, o meu ser reconhecerá apenas aquilo que eu fizer; um objeto só pertencerá a mim se for fundado por mim; e, só reconhecerei meu ser onde ele estiver engajado. Assim, a escritora, ao longo do ensaio, recusará o conselho de Cândido, em que havia dito-lhe para cultivar o nosso jardim; todavia, para ela, não é possível cultivar o nosso jardim, pois sempre cultivarei o meu jardim, em razão de que um jardim só tornar-se-á meu a partir do momento em que o cultivo. Nossas relações com as coisas não são dadas, nem cristalizadas. Nós decidimos a nossa relação com o mundo, mas não de forma arbitrária, pois ao escolhermos, sempre levamos em consideração o passado, uma vez que não podemos construir um futuro sem ele. Cada um, portanto, pode decidir o lugar que quer ocupar no mundo, mas não retirar-se dele, destarte, o ser humano não poderá surgir nele na sua pura ipseidade, sem que ele surja diante de si.

Por conseguinte, Beauvoir demonstra que a fruição não é repouso, não é uma separação do mundo, uma vez que ela supõe a existência do ser no mundo. "A fruição é presença de um objeto no qual me sinto presente" (p. 143); É um instante em que todo o passado se reúne. É um projetar-se no mundo. Assim, o ser do humano não é presença imóvel. Pirro, ao sonhar em partir, já havia iniciado um movimento. Por isso, em concordância com Heidegger, Beauvoir afirma que o "homem [sic! ser humano] é um ser dos longes, ele sempre está alhures" (p. 145). Não há para ele, um lugar singular no mundo no qual ele possa afirmar ser seu, posto que, ele sempre busca outra coisa que não ele mesmo. Logo, ele não pode ser preenchido em sua totalidade. A superação é a sua condição, uma vez superado o dado, seu ser cai no passado, abrindo, assim, "o vazio sempre futuro". Desse modo, a noção de fim, para a autora, é ambígua, em virtude de que todo fim é, simultaneamente, um início, sem impedir que esse fim seja tratado como fim, pois é nesse poder de definir um fim, que reside a liberdade humana.

Embora a ambiguidade seja a condição do ser humano, ele ainda sonha, como expõe a filósofa, com ideal harmônico de Deus, a síntese do em-si e do para-si; ele ainda suplica para os seus atos, um fim incondicionado. Pois bem, e se Pirro justificasse seus projetos como desejos de Deus, eles seriam considerados vãs? Mas é possível um ser que já é, projetar-se? Como fundar um ser que já é? Deus é universal. E universal, de acordo com as palavras da trabalhadora incansável, é silêncio (p. 151). Então, Deus não pode esclarecer os humanos, já que é através deles que se tentará esclarecê-lo. Portanto, retornemos à terra dos humanos. Poderemos encontrar na própria humanidade este fim absoluto que 
buscávamos inicialmente no céu? Afinal, a humanidade é? Podemos falar de uma humanidade? - Interpelou a autora (p. 156), no decorrer do escrito. Decerto, sempre é possível nomear um coletivo, tornar seres humanos unidades que ocupam um espaço, não passando de um "rebanho de animais inteligentes". A humanidade como uma totalidade possui apenas uma única voz; traz consigo não somente o mito da solidariedade, mas também o mito da evolução. Afinal, nós participamos da humanidade?

A autora explicita, após algumas páginas escritas, que a humanidade não é contínua, pois nela há pessoas livres inevitavelmente isoladas por sua subjetividade; que não há entre os humanos uma harmonia preestabelecida; que suas "liberdades não são nem unidas nem opostas: separadas" (p. 158). Por esta razão, é apenas projetando-se no mundo que os humanos situam-se não só a si mesmos, mas também os outros em torno de si. Então, solidariedades se constroem, ainda que não se possa fazer-se solidário de todos, uma vez que se escolhem finalidades. O ser humano, portanto, "está presente no mundo de duas maneiras: ele é um objeto, um dado superado por transcendências estrangeiras; e ele próprio é uma transcendência que se lança para o futuro" (p. 163). Assim sendo, Beauvoir demonstra que é Pirro que tem razão contra o sábio Cineias. Ele parte para conquistar, e depois? Depois ele verá.

Diante desse cenário, em relação ao projeto autêntico do ser humano, a autora não concorda com Heidegger, dado que o humano não é um ser-para-a-morte, ele é um ser mortal. Um ser que é o que ele faz; que escolhe fazer. Com isso, em concordância com Sartre, ela afirma que "não somos para morrer; somos, sem razão, sem fim" (p. 167). Dessa forma, o ser do humano não é estático, ele sempre tem que se fazer ser a cada instante, por isso, ele é projeto. Por mais que nos olhemos no espelho, nos contemos a nós mesmos quem somos, sempre sentiremos que não somos plenamente, que há um vazio. O culto do eu, aqui, já não é possível; a existência de Deus não é provável, a humanidade não se realiza de fato, mas há o outro "diante mim, encerrado em si, aberto ao infinito" (p. 172). No entanto, o que esperamos de outrem?

Ao analisar sua relação com o outro, a autora percebe que ele não é um vazio o qual precisa ser preenchido; que ela não pode descobrir nele nenhuma justificação pronta de si; e que seus atos ao caírem no mundo, criam para ele uma nova situação. Por isso, é necessário que assumamos nossos próprios atos. Os atos humanos, porém, não se propagam ao infinito. Assim, Beauvoir demonstra, ao escrever sobre a dedicação, que posso criar para o outro apenas pontos de partida. $O$ ser que se dedica a outrem, no entanto, quase sempre, pretende preenchê-lo, uma vez que ele se apresenta ao outro, inicialmente, como uma demissão de sua liberdade em favor dele, assumindo, mais tarde, uma figura tirânica. Ao tentar abdicar de sua liberdade, o ser humano a mascara para si, mas a mascara livremente. Para o outro, portanto, sou apenas o instrumento a partir do qual ele se funda. Em vista disso, a escritora escreve que o ser humano "é ao mesmo tempo liberdade e facticidade" (p. 182). O ser humano é livre em situação. 
Independentemente do que quer que eu faça, o outro existe diante de mim, e eu dele. Estou aí, minha existência aparece para ele como tudo o que ele não é, "sou a facticidade de sua situação" (p. 185). O outro é livre, e somente a partir disso, eu também sou. Todos nós fomos lançados no mundo, tentamos fugir à contingência, à gratuidade da pura presença, por isso, precisamos do outro para que a nossa existência se torne necessária e fundada; mas não no sentido hegeliano, como se precaveu Beauvoir, pois o ser do humano, em conformidade com ela, só se realiza em suas ações, em suas obras, é apenas através desses objetos que a sua existência no mundo é realizada, podendo, então, se comunicar com o outro. Logo, o ser do humano só entra em comunicação com o outro através dos objetos nos quais se engaja. Por isso, é de uma liberdade que ele necessita diante de si, dado que ela é não só a única realidade em que ele não consegue transcender, mas também a que pode justificar aquilo que ele fundou, retomando-o sob a sua responsabilidade.

A escritora, posteriormente, retrata a figura do parasita: aquele que ignora o caráter humano dos objetos que faz uso; que não reconhece neles nenhuma marca de liberdade; que vive no seio de uma natureza estrangeira, esmagado pelo peso de coisas inertes (p. 195), sendo ele próprio uma passividade que não se distingue da matéria. Ele só "se torna novamente homem [sic! humano] ao retornar aos seus pares: e então ele se encontra em perigo diante das liberdades deles" (p. 194). É válido lembrar, como preocupou-se em demonstrar Beauvoir, que o ser humano não é livre para tratar, a seu bel-prazer, o outros humanos como coisas; até mesmo o senhor, apesar de sua vontade de cegueira, reconhece que precisa falar com o escravo, embora só se fale com humanos. Destarte, “a linguagem é um chamado da liberdade do outro" (p. 194).

O ser humano, segue escrevinhando a filósofa, realiza-se na medida em que escolhe estar em perigo no mundo, entre liberdades estrangeiras. Quem se nega a enfrentar julgamentos estrangeiros, nega sua liberdade, perde-se. Livre é aquele que se lança no mundo sem aferição, sem cálculo, definindo para si mesmo toda medida, todo desafio. É apenas pelo movimento de liberdade rumo ao seu ser que o ser humano pode confirmar, em seu ser, o outro de quem espera uma justificação necessária de si. Para que os humanos possam dar-lhe um lugar no mundo, é necessário primeiro que ele faça surgir em torno de si um mundo em que eles tenham seu lugar: é preciso amar, querer, fazer. É, pois, sua própria ação que define o público para o qual ele propõe (p. 197). Ora, só posso relacionar-me com pessoas que existam para mim, com as quais criei laços, quer como aliadas quer como inimigas, à proporção que meu projeto se harmonize ou não com o delas.

Como qualquer ser humano, Beauvoir possui uma meta: buscar o ser, pois ao buscar o ser, busca-se ser, em razão de que só há ser através da presença de uma subjetividade que o desvela (p. 198), e é necessariamente do íntimo de sua subjetividade que ela se lança em sua direção. Simone de Beauvoir luta, portanto, para ser. Não no 
sentindo egoísta, pois o ser não permanece em estado de repouso, e não se pode ser sozinho no mundo. Ao lutar-se para ser, abre-se um caminho para o outro, para que o outro reconheça em seu agir, um agir legítimo. Dessa maneira, o respeito pela liberdade de outrem não é uma regra abstrata, mas uma condição primeira para que qualquer agir humano tenha sucesso. O respeito pelas liberdades baseia-se no princípio da igualdade; em todas as situações, a liberdade de outrem é total, uma vez que a situação só existe para ser superada e que a liberdade é igual em toda superação (p. 198). O que é desprezível é a demissão de liberdade. A autora pede para os humanos saúde, bem-estar, lazer, saber, a fim de que a liberdade deles não se consuma combatendo a doença, a miséria, a ignorância. O humano constitui-se através de seu agir. "Ele só é ao transcender-se. Age no risco, no fracasso. Deve assumir o risco: ao lançar-se rumo ao futuro incerto, ele funda com certeza seu presente" (p. 203). Pirro sabe apenas que partirá, mas não para voltar, para conquistar. Mas em nome de quê Cineias julgou o projeto de outrem? Poderia conhecer ele mais do que Pirro suas próprias vontades?

Diante disso, podemos perceber a relevância e atualidade deste ensaio, não muito conhecido no Brasil, uma vez que a maioria das pesquisas trazidas à baila em relação aos escritos da autora está voltada para os assuntos de feminismos, um tema sem dúvida, relevante para mim. Porém, este opúsculo é fundamental para compreendermos o pensamento de Simone de Beauvoir, pois ela inaugura diversos temas que serão não somente retomados em Por uma moral da ambiguidade, mas também aprofundados em seu magnum opus, $\mathrm{O}$ segundo sexo; sem esquecermo-nos das demonstrações feitas do agir humano, em seus romances. A obra é atual, pois questiona vários temas abordados ao longo da tradição filosófica. Demonstra que não há nenhuma divindade por detrás dos atos humanos, portanto, ao agir, o ser humano carrega consigo o peso da responsabilidade. O ser humano é responsável por tudo o que cria no mundo, por todos os laços que constrói, por todos os seus projetos. Há seres que tentarão negar suas liberdades, mas a negarão livremente; há seres que afirmarão suas liberdades, reconhecendo livremente suas responsabilidades.

Assim sendo, e válido lembrar que a autora escreveu o ensaio durante a Segunda Guerra Mundial, em que refletiu sobre a condição da ação humana, em meio de tantas angústias e incertezas. Deste modo, ao escrevê-lo, Beauvoir levou em consideração o contexto histórico e social de sua época. Para ela, o ser humano é ontologicamente livre. O ser humano, no entanto, não possui uma liberdade universal, mas situacional, uma vez que a sua condição é a ambiguidade. Ora, a liberdade humana não é absoluta, desenlaçada do mundo ou independente do outro, pois a liberdade absoluta só seria possível se ela transcendesse todas as outras liberdades; mas se todas as outras liberdades fossem transcendidas, a liberdade que as transcendeu não poderia mais superar a si mesma, tendo em vista que esse movimento ocorre somente com a existência de outra liberdade. E a superação é o movimento ontológico presente no ser do humano. 